\title{
Can "Debate" Transform Teaching and Learning in Higher Education?
}

\author{
Eleftheria Argyropoulou
}

\section{ABSTRACT}

The purpose of this study is to examine post-graduate students' perceptions, feelings, attitudes, and evaluation comments of a debate process they experienced in an Educational Policy, Management and Leadership module during their M.A.(Ed.) studies at a well-known Greek university. Furthermore, it aspires to share the perspective of broadening the teaching methodology in Higher Education using level-appropriate and widely appreciated teaching tools. The study was based on a qualitative design. Findings indicated the benefits gained through the learner-centered structured debate approach emphasized on the development of students' critical, analytical, and communicational skills and stressed their gradual transformation of attitudes. Respondents also stressed active learning and self-driven study, as opposed to the passive learning attained during lectures. Participants' positive feelings constitute the vehicle to the formation and/or transformation of attitudes and the implications of these transformations for their personal and professional life.

Keywords: Educational Leadership and Policy, Higher Education teaching, Structured Class Debate, Transformation of attitudes and feelings.

Published Online: July 26, 2021

ISSN: $2736-4534$

DOI : 10.24018/ejedu.2021.2.3.142

Eleftheria Argyropoulou* University of Crete, Greece. (e-mail: eargirop@ ${ }^{\circledR}$ uc.gr)

*Corresponding author

\section{INTRODUCTION}

Teaching in Higher Education (H.E.) has always been a challenge to scholarship. Laurillard [1] supports that teaching is an important part of $\mathrm{H}$. E. infrastructure and contributes immensely to its change and progress. The most preferred teaching method in H.E. has been the lecture. A discussion has started as to how, what level and why other teaching methods should be introduced in H.E [2] and expand so as to replace lecture, debate being one of them [3], [4]. Relevant literature (see, below) shows the advantages of introducing debate in teaching H.E students in various programmes.

In Greece, debate as a teaching method is not unknown, given that debating and defending juxtaposed ideas or topics is considered a legacy from the classical philosophers. Debate has been introduced as a novelty teaching tool in High School classes [5]. However, debate at university level teaching bears very little research evidence so far [6]. Moreover, using debate as a teaching tool at post-graduate level is sparse.

The present study attempts to fill a potential gap in research concerning the introduction of debate as a teaching method on post-graduate level, with a specific focus on Educational Policy, Management and Leadership MA courses. The challenge lies on the fact that the field of Educational Policy, Management and Leadership has been rapidly developed in recent years, incorporating bulks of knowledge from a variety of corresponding fields and adopting their confusing technical jargon. As a result, understanding, learning, and appropriating knowledge is made difficult for practitioners in education. Given that relevant study material is often in English, students -speakers of other languages have to strive to understand twice as much as native speakers.

The purpose of this study is to examine post-graduate students' perceptions, feelings, attitudes, and evaluation comments of a debate process they experienced in an Educational Policy, Management and Leadership module during their M.A (Ed.) studies at a Greek university. Furthermore, it aspires to share the perspective of broadening the teaching methodology in H.E. by using different teaching methods.

\section{THEORETICAL FRAMEWORK}

The particularity of university teaching lies on the fact that it combines three distinct features: a. cognitive and affective aspects of learning, b. adult learners, c. the dynamics of transformative learning within a discipline-based context. Exploring practical applications arising from these theories and analyzing their implications for university-level teaching [7] should be considered when designing discipline-based curricula and selecting appropriate teaching methods.

\section{A. Learning and Teaching in Higher Education - Challenges}

Learning as an individual and learning from others are the two major perspectives in the way adult students learn, 
appreciate, and evaluate knowledge. Group practices, such as "collaborative learning, are favoured because they actively construct shared understandings ... and classroom debate [helps] to explore and value alternative viewpoints" [7]. Teaching within the humanistic spectrum emphasizes on adult student support and growth, "developing skills in metacognition, reflection, belief systems, self-awareness of study approaches, questioning fixed beliefs, creating a friendly environment encouraging self-learning in addition to group learning".

Illeris [8] suggested a more holistic approach to learning. He integrated both the cognitive and the affective domain in his learning and competence development model. He pointed out on the interaction between the individual and the environment and the variety of individual differences among learners.

\section{B. Adult Learning}

Rogers [9] argues adulthood is characterized by personal development and growth, perspective, and autonomy. Adults carry already shaped and internalized values and experiences, they have formed their own ways of perceiving and learning, their expectations of learning vary dramatically and -quite often- have competing interests. These features underpin the relation between teacher and student and define the goals of adult education and the perspective (conservative or modern, active, freeing) through which the teaching and learning is to be achieved. This dilemma is more difficult in regard to university level adult learning. H.E. teaching and learning is closely interwoven with the discipline content and the amount of new knowledge the individual has to acquire [10]. Everyday practice shows that passive teaching methods are easier, time-gaining, and safer to adopt while a freeing teaching model seems to be "a luxury" and takes place only occasionally. It is necessary to consider critically how the adult person learns involving his/her cognition and emotions and pursuing maximization of critical thinking skills to guide personal and societal transformation. Given the demands and constraints of the modern societies, holistic approaches are preferable [11], [8].

\section{Transformative Learning}

Adult learning is often more than adding information; it has a transformative perspective. "When people revise their habits of mind, they are reinterpreting their sense of self in relation to the world" [12]. This is supported by Kegan's [13] distinction between informative and transformative learning. Mezirow [14] defines transformative learning as "the process by which problematic frames of references (mindsets, habits of mind, meaning perspectives) .... are transformed and made more inclusive, discriminating, open, reflective, and emotionally able to change".

However, if transformative learning is the starting point of teaching, then it should be fostered and challenged by the involvement of specific aspects of adult learning ways: "communicative learning, identification of problematic ideas, beliefs, values and feelings, critical assessment of underlying assumptions ..." [15]. Taylor recognizes the difficulty of contextualizing the principles of transformative learning in classroom practice, so he suggests three core elements to be taken in consideration: individual experience, critical reflection, dialogue; these should be accompanied by a "holistic orientation ... and authentic relationships among teacher and learners and among learners themselves" [15]. The holistic orientation is required for the transformation to be incremental and established, instead of being epochal and superficial [16].

H.E. methods and tools to promote adult learning and transformation: This calls for appropriate curriculum designing and course methods in a discipline - based teaching environment in H.E. There is evidence that academic debate, incorporated within a discipline-based curriculum, demonstrates pedagogical benefits in subjects associated with policy, law, administration, and general social issues; debate is a "content-oriented practice and... tends to highlight important field-specific assumptions and idiosyncrasies of logic that many disciplines do not make plain" [3]. From all types of debate, the Structured Class Debate (SCD) seems the most appropriate to cover the broader goals of a module, from conveying meaningful content to achieving active learning, peer interaction and the development of various academic, professional skills [4]; without ignoring the "mastery of content" the structured debate helps develop critical thinking skills, necessary for career changing, a very common phenomenon in post-modern societies; career changes require high -order thinking skills, such as "defining the problem, assessing the credibility of sources, identifying and challenging assumptions, recognizing inconsistencies, prioritizing relevance and salience of various points..." [17].

In this paper, we use the term "debate" in the form of Structured Class Debate (SCD) and the format we employed is that described by Merrell, Calderwood, and Graham [18].

\section{LITERATURE REVIEW}

Literature review followed a substantial systematic pattern [19]; issue-related criteria have been used for the selection and inclusion of studies. Emphasis was put on debate as learning, teaching, and evaluating method in H.E.; the search expanded from 2000 up to date. Care was taken to examine the existing studies in a quasi- comparative way in order to spot particularities, similarities and /or different aspects of research amongst them; the aim of the systematic review was to underline the complementarity of this study to previous research. The search put forward only two cases in which a sample of Master's degree students [20] and a sample of M.A. and $\mathrm{PhD}$ students [21] had been used.

The most important findings in all papers support that debate is a well-accepted method of teaching, learning and evaluation of learning in H.E classes. It is pointed out that debate as a teaching method enhances higher order thinking skills, such as, analytical skills, critical thinking, analysing ethical issues, the ability to understand and articulate structured, sound and meaningful arguments [4], [21]-[26], and creativity [27]; it also improves cognition by adopting other routes of knowledge acquisition, i.e. learning through various perspectives and methods [3], [28], [29]. Debate develops communication skills and the ability to make ethical decisions, especially important for professions dealing with people, for example doctors, nurses, and therapists [30]-[32], [20]. Certain researchers put forward other features, such as the enhancement of citizenship participation and democracy [4], especially when the SCD is used, while others [33] argue 
that "certain types of debate cannot promote democracy, as they cultivate competition and individualism".

The acquisition of skills mentioned above is per se transformative for the individual, though not explicitly defined by the respondents. However, there are papers where the respondents explicitly support the transformational dynamics of the debate process by pointing out on specific transformations, such as the inhibiting of aggressive behaviours, a social behaviour transformation [3], the students' change of preference towards the teaching method [34], the post-debate transformation of students' attitudes towards the discussed topic [17], [28], [20], while Jagger [25] argues that the debate can lead to potential transformation by "promoting attitudinal change" and Kedraka \& Kourkoutas [6] support that the debate was the vehicle to transformative learning.

Occasionally, the benefits and the positive feelings towards the debate are coupled with criticism and negative feelings. Criticism is associated with the educational and cultural context, the practical application of the debate method, [mis]conceptions of its purpose as a tool in academic learning and students' own fears and feelings [35]-[37], [31], [28], [29], [32]. Some papers echo faculty's reluctance to use the debate method as it is time-consuming and needs more preparation than a lecture [21], not always appropriate for students with different learning paces due to different previous learning approaches [29] or students' lack of desire to participate, of understanding the process and of evaluating the macro -impact of the method [37].

Some papers include extensive reflections of instructors/authors about their own teaching approach and their aim to improve academic teaching [38], [4], [37], a comparison between lecture and debate [34] and an outline of best practices to adopt during debates [4].

\section{METHODS}

The study is based on a qualitative design. It is positioned within the "constructivism" paradigm, as the participants built their knowledge on the experiences, they lived during the debate process and its preparation phase.

The paper seeks to answer the following questions:

a. Is the structured class debate better for MA students than lecture to think and work out on a specific issue or problem?

b. Can transformative learning take place if one is exposed to alternative ways of teaching, such as the debate?

The starting point for this study was the MA students' difficulty in understanding and appropriating the content meaning and the implications of current national and supranational policy content and guidelines for their profession. The author [and instructor of the module] decided to use the SCD to introduce course material and evaluate students' work and understanding. This paper presents students' reflections and evaluation on the introduction of the debate as a teaching method within the MA curriculum.

\section{A. Data Collection and Sample}

Data were collected using a short questionnaire of three open-ended questions on the last day of the M.A. students' attendance of the "Educational Policy, Management and Leadership" module. Data collection took place immediately after the debate workshop. Students had been given material for self-study and preparation of the debate within their teams.

Data were collected from three consequent cohorts over three academic years, 2016-2019. From a total number of 35 M.A. students, 32 responded to the questionnaire. All participants were in the first year of their studies. They had obtained a BA in teaching and worked either in Primary or Secondary State or private schools. Participants were between 25 and 54 years old, the average age being around 40 and they were in various career points. Only six of the respondents were male.

\section{B. Ethical Considerations}

Participation in the study was entirely voluntary. Participants had been informed about the purpose of the study and the data collection time and procedure since the beginning of the course. They were also informed about their right to withdraw any time they felt so.

Participants' identity was codified for anonymity purposes. The following codification pattern was adopted: the capital letters $\mathrm{A}, \mathrm{B}$ and $\mathrm{C}$ were used to denote the cohort and cardinal numbers to denote each participant. Numbering was made at random without implying any participant characteristic. Participants' code labeling had the final form of A01, B01, $\mathrm{C} 01$, etc. The anonymity code had been printed on each answer sheet before the students' completion of the questionnaire took place.

\section{Analysis}

Analysis of the data was supported by MAX QDA2018.2 [VERBI] software. Three document sets were made corresponding to the cohort-participant pattern shown above. The respondents' answers were typed verbatim and imported in the software. Care was taken to eliminate any possible change in the participants' words to avoid any interference from the researcher. The aim was to ensure credibility and authenticity for the entire research process [39].

Thematic Analysis was chosen as the best way to approach participants' views and attitudes towards the research questions. Additionally, open coding was adopted [40]; it was performed in two directions, from text to codes and from codes to text [39], in order to ensure that analysis would not be biased. Codes were constructed and applied thrice before the researcher was satisfied with the code content and indicators, so as to be able to assign coders to categories in a consistent and confident way. All texts were thoroughly read once again, and the appropriate codes were assigned to the corresponding segments. After that, coded segments were reread to ensure that they fell into the categories they had initially been assigned to.

\section{FINDINGS}

\section{A. Thematic and Category-based Analysis}

\section{Knowledge Acquisition}

Respondents pointed out on two major ways of knowledge acquisition through the debate and pre-debate process. 


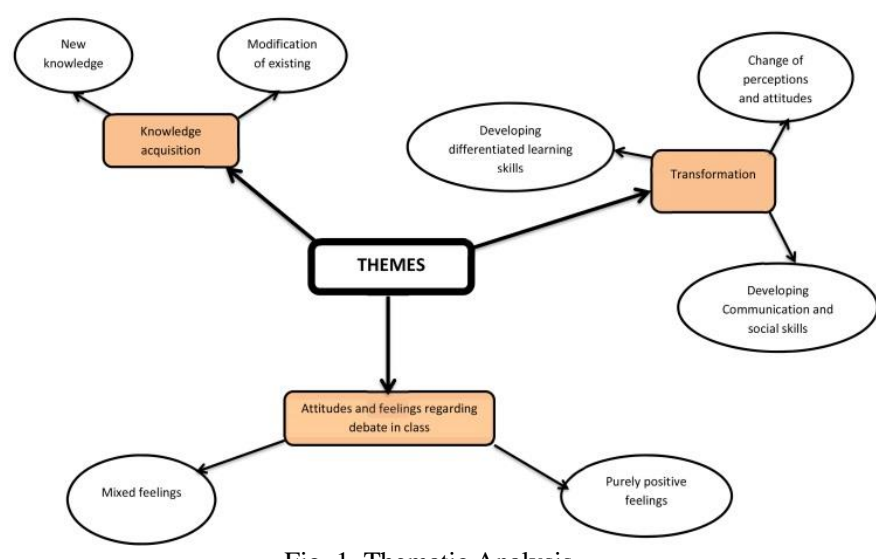

Fig. 1. Thematic Analysis.

2. Acquisition of New Knowledge

Twelve participants shared the perspective that the debate led them to new knowledge. They mostly referred to knowledge they did not possess before starting the course, but they considered necessary in order to take part in the debate, a fact that led to personal enquiry. However, the majority of relevant answers pointed on two specific issues: learning about new trends and management in education-specific information and terms and jargon. Modification and Appropriation of Existing Knowledge Seventeen respondents emphasized on the opportunity they had to realize the meaning of the issues in discussion and to probe into their deeper implications; to unravel the unseen aspects of things they thought up to then that they concerned only Tertiary Education, not Primary or Secondary.

References on understanding and deepening knowledge were the most frequent in this category. In some cases, the debate produced reflection on the role of the teacher both in society and the school and how it is or should be transformed in the future.

\section{Transformation}

The participants emphasized on the knowledge and skills they gained and how they transformed their abilities, perceptions, and attitudes towards learning and in some cases- their way of teaching.

\section{B. Developing Differentiated Learning Skills}

Almost all references in this category pointed on the differentiated leaning which they called peer learning, that is, learning from others either during their work and study in their group or during the juxtaposition of arguments on the day of the debate. Interaction was of prime importance to their way of learning.

Another aspect of differentiated learning was put forward: encouraging critical thinking and broadening perspectives, thus gaining a holistic understanding; the debate is described as an active learning process (not passive, as it happens in lectures) because it leads to self-activation [i.e., wishing to take part, to express opinion, to interact with the rest of the discussants] and to self-driven study; self-driven study before the debate process was thought necessary for the students to be ready and well-equipped to discuss. Another participant commented on the fact that the debate promotes a studentcentered teaching style.

\section{Developing Social and Communicational Skills}

Most participants welcomed the fact that debate provides $a$ chance for everyone to speak, to be heard in a larger audience of peers, to interact with significant others, to cooperate with peers in a team, to exchange ideas and views. Interaction was given much emphasis by 10 respondents. Similarly, debate encourages self-activation and a larger engagement in the discussion. Even timid persons learn the ropes of expressing themselves openly and freely in public and manage shyness. Some people pointed out on the cultivation of democratic values and exercising a civilized way of discussing when you are in a larger audience.

\section{Change of Perceptions and Attitudes}

Fifteen people mentioned that debate helped them change the perceptions they had already had about knowledge, its role and function in the meta-modern era. They admitted that their perceptions so far were rather superficial, and debating helped them approach things in a probing way. Exchange of information from the study material with peers led them to understand changes in society, economy, and the provision of education. Some others pointed on their change of attitudes regarding lifelong learning in relation to their own teaching practice. A few respondents raised a criticism against what goes on in education.

\section{E. Attitudes and Feelings towards the Debate Method}

Respondents expressed quite positive feelings towards the debate methodology. However, some were more cautious than others regarding certain aspects of the process.

\section{F. Mixed Feelings}

As this teaching process was totally new to all students, fifteen of them had mixed feelings, especially before it, including anticipation anxiety for something they had never experienced before, awkwardness during the process and difficulties during the preparation study.

\section{G. Purely Positive Feelings}

All participants stated that the SCD was effective in a variety of ways:

a. the comparison between traditional ways of teaching and learning and the methodology of debate,

b. appropriateness of the debate for adult learning postgraduate studies,

c. positive comments and feelings,

d. substantiation of positive comments: students explain why they were positive; they made an "abundant" use of adjectives to express their emotions towards the debate.

\section{OVERVIEWS}

\section{A. Overview 1-Visualizations of Results}

The tools provided by the MAXQDA help visualize the most frequently assigned codes across all answers. The Code Cloud (Fig. 2) shows that the vast majority of students' Answers are clustered around the major category.

\section{B. Pure Positive Feelings}

The shading and the letter size indicate the importance students attribute to thematic categories and subcategories. The three subcategories regarding knowledge and comprehension and the subcategory of social and 
communicational skills serve as the basis for the creation of feelings and the change of perceptions and attitudes. In other words, knowledge functions as the foundation of personal transformation provided that it is meaningful, motivating and enjoyable for the individual.

\section{ACQUISITION OF NEW KNOWLEDGE MODIFICATION AND APPROPRIATION OF EXISTING KNOWELDGE \\ POsit

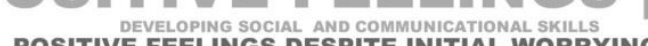 OSITIVE FEELINGS DESPITE INITIAL WORRYING DEVELOPING DIFFERENTIATED LEARNING SKILLS}

Fig. 2. The Code Cloud.

\section{Overview 2 -Relationships between Categories}

The Code Relations Browser (Table I) indicates that there is a close relation and co-occurrence of two codes in segments across multiple categories and outlines that:

a. the change of perceptions results from the various aspects of the cognitive process, knowledge acquisition, knowledge modification and new learning skills; they co-occur from 19 to 4 times the social and communicational skills being the weakest example;

b. there is a cross-section between the four categories indicating different aspects of the cognitive process; however, only the skills subcategories contribute strongly to the formation of positive feelings even with some criticism; they co-occur 19 times with pure positive feelings and 4-10 times with positive feelings including some criticism, social communicational skills being the least favorable as they triggered awkwardness;

c. peer learning has been assigned to cognitive skills; nevertheless, it also falls into the socialcommunicational skills, in the sense that it requires essential communicational skills for the individual in order to be effective; this means that for some participants it could have triggered positive but somehow awkward feelings. For those participants, transformation of perceptions and/or attitudes seems minimal or absent

\section{DISCUSSION}

This study presents MA students' perceptions of the debate as a teaching and evaluating tool within the MA curriculum. The instructor's goal was to help students familiarize with relevant jargon, understand the discipline-based material, be critical, analytic, and able to synthesize the course material and, thus, successfully fulfill the requirements of the module. Students' answers show the goal was attained, as they increased their informative knowledge, mastered the jargon, had the chance to probe into things they had not paid attention before and developed transformative knowledge. The participants pointed out on the knowledge they did not possess before starting the course, but they considered necessary in order to take part in the debate, their learning about new trends and management in education-specific information, and the apprehension of terms and technical jargon. Similar results were reported by previous research: Omelicheva \& Avdeyeva [34] reported that "debates appear to be more effective in developing students' comprehension of complex concepts", Mumtaz \& Latif [32] stated "[students] learned more about controversial topics", Vo and Morris [23] showed high scores "in learning and understanding of the course, ... [and] ... of ... problems and issues", Williams, Mc Gee \& Worth [22] reported a benefit "from general knowledge acquisition". Also, Hanna et al [20] mentioned that "knowledge and understanding ... had improved" and Scott [24] concluded that participants "learned new knowledge, gained an understanding of the topic and gained additional knowledge on the subject". Keller, Whittaker \& Burke [35] also stressed the contribution of debate to the better knowledge of the topic.

\begin{tabular}{|c|c|c|c|c|c|c|c|}
\hline Code System & $\begin{array}{l}\text { Modification and } \\
\text { appropriation of } \\
\text { existing } \\
\text { knowledge }\end{array}$ & $\begin{array}{l}\text { Acquisition } \\
\text { of new } \\
\text { knowledge }\end{array}$ & $\begin{array}{l}\text { Developing } \\
\text { differentiated } \\
\text { learning skills }\end{array}$ & $\begin{array}{c}\text { Developing } \\
\text { social and } \\
\text { communicatio } \\
\text { nal skills }\end{array}$ & $\begin{array}{l}\text { Change of } \\
\text { perceptions } \\
\text { and attitudes }\end{array}$ & $\begin{array}{l}\text { Positive } \\
\text { feelings } \\
\text { pure }\end{array}$ & $\begin{array}{c}\text { Positive } \\
\text { feelings } \\
\text { despite initial } \\
\text { worrying } \\
\end{array}$ \\
\hline $\begin{array}{l}\text { Modification and } \\
\text { appropriation of } \\
\text { existing knowledge }\end{array}$ & 0 & 6 & 2 & 0 & 6 & 1 & 2 \\
\hline $\begin{array}{l}\text { Acquisition of new } \\
\text { knowledge }\end{array}$ & 6 & 0 & 3 & 1 & 5 & 1 & 2 \\
\hline $\begin{array}{c}\text { Developing } \\
\text { differentiated } \\
\text { learning skills }\end{array}$ & 2 & 3 & 0 & 3 & 2 & 8 & 5 \\
\hline $\begin{array}{l}\text { Developing social } \\
\text { and } \\
\text { communicational } \\
\text { skills }\end{array}$ & 0 & 1 & 3 & 0 & 0 & 8 & 2 \\
\hline $\begin{array}{c}\text { Change of } \\
\text { perceptions and } \\
\text { attitudes }\end{array}$ & 6 & 5 & 2 & 0 & 0 & 0 & 0 \\
\hline $\begin{array}{c}\text { Positive feelings } \\
\text { pure }\end{array}$ & 1 & 1 & 8 & 8 & 0 & 0 & 6 \\
\hline $\begin{array}{c}\text { Positive feelings } \\
\text { despite initial } \\
\text { worrying }\end{array}$ & 2 & 2 & 5 & 2 & 0 & 6 & 0 \\
\hline
\end{tabular}


The findings provided sufficient answers to the research questions. The student-centered process and the absence of the teacher authority -in comparison to lecture- encouraged students to seek further knowledge on their own, think critically and broaden their perspectives. Students emphasized on active learning and self-driven study as opposed to the passive learning attained during lectures. By "self-driven study" -the students explained- they were prompted to search further on their own about "tacit" information they lacked. This is in accordance with Vo \& Morris' findings [23] on long-termed research skills enhancement, Williams, Mc Gee \& Worth [22] and Hall [31] reporting on "the development of research skills" and SmithRandolph's [37] participants arguing that the "use of debate forced them to be more active in their learning". Kedraka \& Kourkoutas [6] also reported students' appreciation of the energetic way of learning promoted by the debate, as compared to traditional lectures.

The participants in this study seemed more reflective about issues denoting parameters of the educational process. This can be explained by the fact they are teachers themselves. They commented on the method appropriateness for their level of study, and they pointed out the importance of working together in teams and finding out a new way of learning from each other (peer learning). Development of teamwork skills is also reported in previous research, though the mentions are few [20], [6].

Findings also indicated the development of critical and analytical skills, which had been the most stressed findings in the existing literature [6], [23], [22], [24]. Students were exposed to a wide range of viewpoints, engaged in a discussion to question, or support them, to probe deeper into the unseen aspects of policies and their implications for the teaching profession, analyze and synthesize all points of view in a creative way, thus, benefiting from the peers' contributions.

Interaction enhanced students' communication and other social skills. Previous researchers also reported similar findings: Hanna et al [20] talked about students' enhanced ability to communicate and share information with others, Mumtaz \& Latif [32] stressed the development of listening skills, being open to different points of view and able to answer questions to larger groups of people, Goodwin [36] pointed on the learning of effective communication strategies and group work, Onen [21] reported enhancement of oral communication skills, while Williams, Mc Gee \& Worth [22] found that the social skills acquired during the debate led to students' self- esteem and self-confidence. Even shy students had the chance to engage in the discussion and overcome their shyness, as the whole procedure was based on democratic values and was carried out in a civilized way.

Transformation was the most significant finding. Debate led to reconsidering perceptions and attitudes towards policies and theoretical stances and their role and practice as teachers. The transformational dynamics of the SCD have also been identified in the works of Kedraka \& Kourkoutas [6], Hanna et al [20], Kennedy [17] reporting a change of opinion, and Omelicheva \& Avdeyeva [34], although the latter supported that "the change in the students' opinion occurred largely due to the deliberation accompanying the debates". The participants of this study explicitly indicated the way the debate contributed to their gradual transformation of attitudes. Due to their educational background, they could define the content of transformation more clearly, though the persistence and the continuation of the new behaviour in their personal and professional lives cannot be traced by this study. In Mezirow's [16] words, this transformation is "epochal" and -at that moment of research- it could not be foreseen as an established norm of behaviour.

However, what underlies all these findings are the participants' feelings. The Code Cloud indicates that the stronger thematic category includes the participants' Positive Feelings. The frequency of occurrence of the subcategory Positive Feelings -pure and its co-occurrence and crosssection with the other cognitive subcategories in the Code Relation Browser- denotes their strong interactive relation. Participants' positive feelings, either pure or with some kind of indirect criticism towards certain aspects of the debate process, constitute the vehicle to the formation or transformation of opinions towards the course content, method, delivery of the course material and the implications of these transformations for their personal and professional life. This finding is in accordance with the theoretical assumptions about the importance of the affective domain in the attitudinal and behavioral development [25] and the initiation of the critical and reflection process; it can lead to "switch in beliefs" echoed in Cranton's view that "a deeply felt, positive experience(s) ... leads to questioning of either personal habits of mind or perspectives on the world" [12]. It is also coupled with relevant research findings regarding emotional involvement for or against the debate method [34], [37], [23]. Though there were minor negative comments and/or criticism in this study- mostly due to personal traits and reservations and similar to those depicted in some of the previous studies-, the participants used strong adjectival language to describe their perceptions and the benefits they gained through the debate process. In previous research, respondents' criticism towards the debate were somehow different and included negative comments about competitiveness [36], [33], lack of preparation, timeconsumption, stress, and frustration associated with final assessment and lower marks, discrepancies during the process itself, participants' sex and beliefs [37], [32], [31], [38].

\section{LIMITATIONS, FUTURE RESEARCH AND IMPLICATIONS}

This study is qualitative, small-sample, perception-based and mirroring the specific course experiences and expectations; consequently, it is subject to contextual constraints and validity issues. Though it indicates the positive outcomes of the integration of the debate method across discipline curricula, it calls for further research on the process itself, its best practices in university classes, its comparison with other H.E. teaching practices and its investigation with quantitative and other qualitative tools in order to provide more solid and sound results to the academic community. The transforming dynamics of the Structured Class Debate should be further examined. Based on the fact that debate teaching is student-centered, there should always be a post-debate debriefing section, during which students should be able to discuss openly the transformational 
dynamics, analyze advantages and drawbacks and establish a "solid ground" for maintaining the change in their practice.

\section{REFERENCES}

[1] Laurillard, D. (ed.), Rethinking University Teaching: a framework for the effective use of learning technologies, $2^{\text {nd }}$ edition, London - N.Y., Routledge-Falmer, 2002.

[2] Trigwell, K., Scholarship of teaching and learning, in L. Hunt \& D. Chalmers (eds,) University Teaching in Focus (pp. 253-267), Victoria, Australia, Routledge-ACER, 2013.

[3] Bellon, J., A Research-based Justification for Debate across the Curriculum, Argumentation and Advocacy, 36 (3), 161-175, 2000.

[4] Oros, A.L., Let's Debate: Active Learning encourages Student Participation and Critical Thinking, Journal of Political Science Education, 3 (3), 293-311, 2007.

[5] Egglezou, F., Debate and argumentation in the language teaching, $1^{\text {st }}$ PanHellenic Conference of School Advisors "Modern Teaching Approaches" [in Greek] available on http://www.pess.gr/synedria/1synedrio/anakoinoseis/86-1o-panelinio-synedrio-sxolikwnsymvoulwn.html., 2013.

[6] Kedraka, K. \& Kourkoutas, Y., Debates in teaching Bioethics, Journal of Curriculum and Teaching, 7(1), 32-41, 2018.

[7] Stewart, M., Understanding Learning: Theories and Critique, in L. Hunt \& D. Chalmers (eds.), University Teaching in Focus: a learningcentered approach (pp.3-20), London and N. Y.: Routledge- ACER, 2013.

[8] Illeris, K., A comprehensive understanding of human learning, in K. Illeris (ed.) Contemporary Theories of Learning (pp. 1-13), London and N.Y, Routledge, 2018.

[9] Rogers, A., Teaching Adults, Athens, METAIXMIO publications (Greek translation), 1999.

[10] Land, R., Discipline-based Teaching, in L. Hunt \& D. Chalmers (eds), University Teaching in Focus: a learning-centered approach (pp. 3855). Victoria, Australia, Routledge-ACER, 2013.

[11] Merriam, S.B., Adult learning theory: evolution and future directions, in K. Illeris (ed.), Contemporary Theories of Learning (pp.83-96), London and N.Y., Routledge, 2018.

[12] Cranton, P., Understanding and Promoting Transformative Learning: A guide to theory and practice. Stirling, Virginia, Stylus Publishing, LLC, $3^{\text {rd }}$ edition, 2016.

[13] Kegan, R., What "form" transforms? A constructive-developmental approach to transformative learning, in K. Illeris (ed.) Contemporary Theories of Learning London and N.Y.: Routledge, 2018, (pp. 29-45).

[14] Mezirow, J., Transformative learning theory, in K. Illeris (ed.), Contemporary Theories of Learning, London and N.Y.: Routledge, 2018, (pp. 114-128).

[15] Taylor, E., Fostering Transformative Learning. In J. Mezirow, Ed. Taylor \& associates (eds), Transformative Learning in Practice, S.F.: Jossey-Bass, 2010, (pp. 3-17).

[16] Mezirow, J., Learning to think like an adult: Core concepts of transformation theory, in E.W. Taylor \& P. Cranton (eds), The handbook of transformative learning: Theory, research and practice, S.F., CA: Jossey-Bass, 2012, (pp. 73-96).

[17] Kennedy, R., The power of in-class debates, Active Learning in Higher Education, 10 (3), 225-236, 2009.

[18] Merrell, B., Calderwood, K. \& Graham, T., Debate across the Disciplines: Structured Classroom Debates in Interdisciplinary Curricula, Contemporary Argumentation and Debate, 37 (0), 57-74, 2017.

[19] Hammersley, M., On 'Systematic' Reviews of Research Literature: a 'narrative' response to Evans \& Benefield, British Educational Research Journal, 27, (5), 543-554, 2001.

[20] Hanna, L., Barry, C., R., Donnely, R., Hughes, F., Jones, D., Laverty, G. Parsons, C. \& Ryan, C., Instructional Design and Assessment, Using Debate to Pharmacy Students About Ethical Issues, American Journal of Pharmaceutical Education, 78(3), 1-8, 2014.

[21] Onen, D., Using Debate to Teach: A Multi-skilling Pedagogy often neglected by University Academic Staff, International Journal of Learning, Teaching and Educational Research, 15 (7), 110-126, 2016.

[22] Williams, D.E., McGee, B.R. \& Worth, D.S., University Student Perceptions of the Efficacy of Participation: An Empirical Investigation, Argumentation and Advocacy, 37(4), 198-209, 2001.

[23] Vo, H.X. \& Morris, R.L., Debate as a Tool in Teaching Economics: Rationale, Technique and Some Evidence, Journal of Education for Business, 81(6), 315-320, 2006.
[24] Scott, S., Perceptions of Students' Learning Critical Thinking through Debate in a Technology Classroom: A Case Study, Journal of Technology Studies, 34(1), 39-44, 2008.

[25] Jagger, S., Affective learning and the classroom debate, Innovations in Education and Teaching International, 50 (1), 38-50, 2013.

[26] Brown, Z., The use of in-class debates as a teaching strategy in increasing students' critical thinking and collaborative learning skills in higher education, Educational futures, 7 (1), 39-55, 2015.

[27] Zawawi, A.A., Ismail, J, \& Hakimi I.N.M., Creativity in Higher Education: The Impact of Classroom Debate on the Academic Performance of Administrative Science Students, Journal of Administrative Science, 15(3), 1-8, 2018.

[28] Healy, R., The power of debate: Reflections on the potential of debates for engaging students in critical thinking about controversial geographical topics, Journal of Geography in Higher Education, 36 (2), 239-257, 2012.

[29] Souza, C., Debating: a catalyst to enhance learning skills and competencies, Education + Training, 55 (6), 538-549, 2013.

[30] Griswold, L.A., Debate as a Teaching Strategy, The American Journal of Occupational Therapy, 54(4), 427-428, 2000.

[31] Hall, D., Debate: Innovative Teaching to Enhance Critical Thinking and Communication Skills in Healthcare Professionals, The Internet Journal of Allied Health Sciences and Practice, 9(3), 1-8, 2011.

[32] Mumtaz, S. \& Latif, R., How we teach Classroom and Laboratory Research Projects, Learning through debate during problem-based learning: an active learning strategy, Advances in Physiology Education, 41, 390-394, 2017.

[33] Tumposky, N.R., The Debate Debate, The Clearing House: A Journal of Educational Strategies, Issues and Ideas, 78 (2), 52-56, 2004.

[34] Omelicheva, M.Y. \& Avdeyeva, O., Teaching with Lecture or Debate? Testing the Effectiveness of Traditional versus Active Learning Methods of Instruction, PS: Political Science and Politics, 603-7, 2008.

[35] Keller, T., Whittaker, J. \& Burke, T., Student debates in policy courses: promoting policy practice skills and knowledge through active learning, Journal of Social Work Education, 37 (2), 343-355, 2001.

[36] Goodwin, J., Students' Perspectives on Debate Exercises in Content Area Classes, Communication Education, 52(2), 157-163, 2003.

[37] Smith Randolph, D., Student perceptions of the use of debate as a teaching strategy in the allied health professions, Journal of Allied Health, 36 (1), 13-29, 2007.

[38] Darby, M., Debate: A Teaching-Learning Strategy for Developing Competence in Communication and Critical Thinking, Journal of Dental Hygiene, 81(4), 1-10, 2007.

[39] Kuckartz, U., Qualitative Text Analysis: A Guide to Methods, Practice and Using Software. L.A., London, N.D., Singapore, Washington, D.C.: SAGE, 2014.

[40] Male, T., Analysing Qualitative Data, in I. Palaiologou, D. Needham \& T. Male (Eds), Doing Research in Education: Theory and Practice (pp.177-191), London: SAGE, 2016.

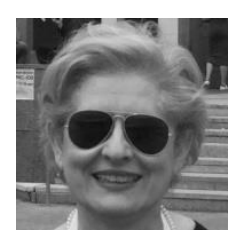

Dr Eleftheria Argyropoulou is an Associate Professor in the School of Education, Department of Preschool Education, University of Crete, Greece and course director of the M.A programme "Management and Training Needs for teachers and Headteachers" in the same Department. Her subject area is Management and Leadership in Education. She has written four books on Management, Educational Planning and Economics in Education and Ethical Leadership (in Greek) and has written several research papers in English, French and Greek. She has participated in more than 25 international conferences, most of them as an invited or keynote speaker. She has also been a partner in six international research programs.

Dr Argyropoulou's interests include a/ the aspect of Ethics in general Educational and School Leadership, especially within the context of crises and recession, $\mathrm{b} /$ the impact of crises on school management and legislative regulation, c/ educational policies affecting Headteachers' selection, $d /$ the critical approach to educational policy ethics.

Some of her latest articles include:

1. Palaiologou, I., Argyropoulou, E., Styf, M., Arvidsson, C., Ince, A., and Male T., (2021), Pedagogical Leadership: A comparative study from England, Greece and Sweden, in M., Sakr, and $O^{\prime}$ Sullivan, J., (Eds) Enabling Pedagogic Leadership in Early Childhood Education, London: Bloomsbury Publishing Plc.

2. Argyropoulou, E., Syka, Ch. \& Papaioannou, M. (2021) School Leadership in Dire Straits: Fighting the Virus or Challenging the Consequences?, International Studies in Educational Administration, 49 (1), 18-27. 
3. Argyropoulou, E. (2020) Lying in the teaching profession: using mixed methods to challenge teachers' honesty and choices to critical incidents, International Journal of Ethics Education, 5 (2), 243-259, doi.org/10.1007/s40889-020-00099-8.

4. Argyropoulou, E. (2018) International Organizations of Educational Planning, Government Policies and School Management and Leadership, China-USA Business Review, Vol. 17, No. 2, 53-63.

5. Eliophotou-Menon, M., Argyropoulou, E. and Stylianou, A (2018): Managing the link between higher education and the labour market: perceptions of graduates in Greece and Cyprus, Tertiary Education and Management, 298-310, doi.org/10.1080/13583883.2018.1444195 